\title{
INTEGRALNI INDEKS UČINKOVITOSTI MALOG I SREDNJEG DRVNO INDUSTRIJSKOG PROIZVODNOG PODUZEĆA FINALNIH PROIZVODA
}

\section{INTEGRAL PERFORMANCE INDEX OF SMALL AND MEDIUM WOOD INDUSTRIAL FINANCIAL PRODUCTS}

\author{
Drago BIONDIĆ
}

\begin{abstract}
SAŽETAK:
U ovom članku želi se u skraćenom obliku prezentirati relativno jednostavna metodologija integralnog ocjenjivanja učinkovitosti te mogućnost njezine primjene u malim i srednjim proizvodnim drvno industrijskim poduzećima. Metoda je uz određene prilagodbe elemenata ocjenjivanja primjenjiva u svima industrijskim granama, kao i u uslužnim djelatnostima. Integralna ocjena učinkovitosti je u funkciji postizanja izvrsnosti u poslovanju. Sama metoda ocjenjivanja učinkovitosti obuhvaća usporednu analizu u odnosu na željeno stanje i dijelom dubinsku analizu rezultata poslovanja. Integralna ocjena učinkovitosti obuhvaća sistematično usporedno preispitivanje ostvarenih rezultata po elementima, funkcijama i organizaciji u cjelini. U suženom formatu metoda se na osnovi percepcije rezultata poslovanja u odnosu na željeno stanje može uz prethodnu kratku edukaciju rukovodstva primjenjivati za samoocjenjivanje poslovanja drvno industrijskog poduzeća. Objektivnije ocjenjivanje učinkovitosti kroz detaljnu primjenu metodologije može se ostvariti kroz angažiranje interdisciplinarnog tima konzultanata. Pri tome rukovodstvo i svi djelatnici poduzeća tijekom rada konzultanata u poduzeću trebali bi biti otvoreni za suradnju. Suradnja s konzultantima uz zaštitu tajnosti podataka poduzeća, obuhvaća analizu dokumentacije, snimanje i pregled tehničkih i ekonomskih podataka, intervjuiranje djelatnika na svim razinama, intervjue dionika iz okruženja te proračunavanje svih koeficijenata, udjela i stopa koji se mogu uspoređivati sa željenim stanjem. Osim toga, u vrlo skraćenom obliku navest će se podaci integralne ocijene indeksa učinkovitosti po elementima, funkcijama i organizaciji u cjelini za jedno zamišljeno poduzeće koje proizvodi namještaj od masivnog drva po nacrtima kupca.
\end{abstract}

KLJUČNE RIJEČI: poslovna izvrsnost, učinkovitost, integralni pristup, ocjenjivanje učinkovitosti, interdisciplinarni pristup, percepcija, željeno stanje, uvođenje promjena u poslovanju

\section{UVOD}

\section{INTRODUCTION}

Mnogi stručnjaci, uključujući Adama Granta, rekli su da uspjeh i sreća pripadaju ljudima koji mogu kontrolirati svoju pažnju što znači naglasili su važnosti fokusa. Još 1971. psiholog Herbert A. Simon naglasio je da bogatstvo informacija znači nestašicu pozornosti. Da bi se rukovodstvo poduzeća moglo fokusirati na povećanje konkurentnost i postizanje izvrsnosti u poslovanju, trebalo bi u svakom momentu znati integralno stanje indeksa učinkovitosti poslovanja. 


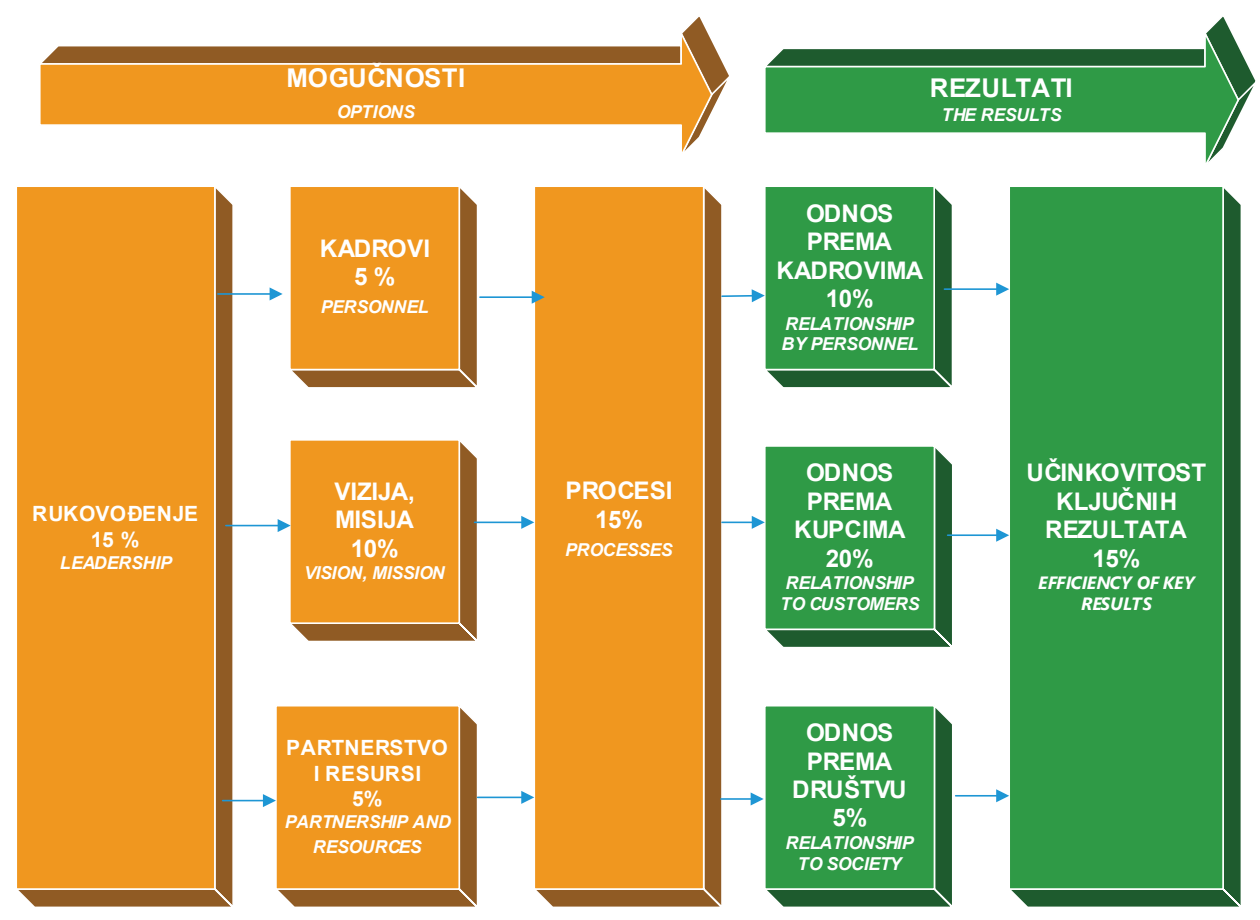

Velike kompanije Simens, BMW, Vodafone i druge, za praćenje učinkovitosti poslovanja poduzeća u realnom vremenu koriste skup softver tvrtke Celonis u kojima su prisutni i elementi umjetne inteligencije, a sve u cilju unapređivanja poslovanja. Prema iskustvu korisnika ti sustavi djeluju poput rendgenske slike poslovanja, što omogućava uočavanje područja neučinkovitosti u kojima se trebaju provesti promjene i unapređenja.

Za mala i srednja drvno industrijska poduzeća takav softver je neprikladan po složenosti i cijeni. Prema praktičnim saznanjima o problemima upravljanja već više godina radimo na razvoju metodologije i na automatskoj obradi podataka za integralno ocjenjivanja stanja učinkovitosti, kako bi mali i srednji poduzetnici drvno industrijskih poduzeća u roku tri do pet dana mogli što objektivnije sagledati područja i opseg potrebnih promjena, a sve u cilju povećanja konkurentnosti. Metodologija integralne ocjene stanja indeksa učinkovitosti bazira se na EU modelu poslovne izvrsnosti (EFQM - model) slika 1.

\section{OSNOVNA POGLAVLJA BASIC CHAPTERS}

U radu će se ukratko obraditi osnovne funkcije drvno industrijskih poduzeća i pojmovi vezani za učinkovitost. Definirat će se ciljevi ocjenjivanja učinkovitosti i opis načina provođenja. Osim toga navest će se elementi ocjenjivanja učinkovitosti sa rezultatima za jedno zamišljeno poduzeće koje proizvodi namještaj od masivnog drva i to za rukovođenje, kadrove, proizvodni programa, prodaju proizvoda i usluga, nabavu i kooperaciju, organizaciju i informatizaciju, proizvodnju, rast i razvoj te financije. Konačno će se prezentirati indeks učinkovitosti uz definiranje područja neučinkovitosti zamišljena poduzeća koje proizvodi namještaj od masivnog drva prema nacrtima kupca. U zaključku će se sagledati mogućnost i opravdanost primjene metodologije integralne ocjene učinkovitosti u malim i srednjim poduzećima.

\subsection{Osnovne funkcije poduzeća i pojmovi vezani za učinkovitost - Basic company functions and performance concepts}

Proizvodna organizacija je gospodarska cjelina koja je nastala svjesnim udruživanjem ljudi kako bi se koordiniranim aktivnostima uz korištenje sredstva za rad ostvarili točno određeni ciljevi. Osnovne funkcije su rukovođenje, kadrovi, proizvod, prodaja proizvoda i usluga, nabava materijala i kooperacija, organizacija i informatizacija, proizvodnja, rast i razvoj te financije. Učinkovitost je ostvareno postignuće u poslovanju u odnosu na željeno stanje izvrsnosti.

$$
\begin{gathered}
\text { Indeks učinkovitosti }(\%) \text { = ostvareno postignuće / } \\
\text { željeno stanje izvrsnosti } \mathrm{x} 100
\end{gathered}
$$

\section{Performance Index (\%) = Achieved Achievement /} Desired Excellence $\mathrm{x} 100$

Poslovna izvrsnost predstavlja standarde za mjerenje učinkovitosti svih izravnih i neizravnih dionika u poslovanja te organizacije u cjelini. Integralni ili holistički pristup ocjenjivanja učinkovitosti podrazumijeva djelovanje kada se elementi i funkcije poduzeća promatraju kroz stanje sustava, a ne zasebno. Percepcija je proces u kojemu mozak 
subjekta organizira podatke dospjele iz raznih izvora te ih na temelju raznih iskustava interpretira tvoreći smislenu cjelinu. Interdisciplinarni pristup predstavlja vrstu suradnje u kojem stručnjaci različitih akademskih disciplina rade na realizaciji zajedničkih ciljeva.

\subsection{Cilj ocjenjivanja učinkovitosti i opis načina provođenja - The objective of evaluating performance and describing how it is implemented}

Malim i srednjim poduzetnicima trebao bi biti u interesu integralno ocjenjivanje stanja učinkovitosti, kako bi u kratkom roku mogli sagledati područja i opseg potrebnih promjena i poboljšanja u poslovanju radi povećanja konkurentnosti. Na osnovi odgovora na pitanja kod intervjua ili analize činjenica prema željenom stanju te izračunatih stopa, koeficijenata, postotnih udjela ili relativnih iznosi prema željenom stanju ili istom takvom statističkom podatku predviđena su tri nivoa raspona ocjena i to: nikakva do minimalne učinkovitost u odnosu na željeno stanje $(1,0$ - 3,5); djelomično zadovoljavajuća učinkovitost u odnosu na željeno stanje (3,6 - 4,5); zadovoljavajuća do željene učinkovitosti $(4,6-5,0)$. Ocjenjivanje podataka koji su iz istog razdoblja obavlja se po linearnoj interpolaciji,

$$
\begin{gathered}
\text { Ocjena }=(5-1) /(\mathrm{V} 5-\mathrm{V} 1)(\mathrm{V}-\mathrm{V} 1)+1 \text { pri čemu je } \\
\text { V5 - vrijednost parametra za ocjenu } 5 ; \\
\text { V1 - vrijednost parametra za ocjenu } 1 ; \\
\text { V - „izračunata“ vrijednost }
\end{gathered}
$$

Za svaku ocjenu predviđen je postotni intenzitet utjecaja pojedinog elementa i funkcije na učinkovitost te pojedinih funkcija na učinkovitost poduzeća u cjelini. Postotni intenzitet utjecaja minimalno može biti $5 \%$, a drugi veći intenzitet utjecaja mora biti djeljiv sa $5 \%$, s tim da zbroj postotnih intenziteta utjecaja elemenata u jednoj funkciji (ili svih funkcija u poduzeću) mora biti $100 \%$.

\subsection{Rukovođenje - Leadership}

Ocjenjivanje stanja učinkovitosti rukovođenja obuhvaća elemente kao što su: primjena modernih principa rukovođenja, primjena rukovođenja prema viziji, misiji i ciljevima, rukovođenje ljudskim potencijalom, uspješnost upravljanja kapitalom, uspješnost upravljanja radnim procesima, zadovoljstvo korisnika, zadovoljstvo djelatnika, održivost, zaštitu okoliša te zadovoljstvo društvene zajednice. Učinkovitost rukovođenja za zamišljeno proizvodno poduzeće ocjenjivana je prema metodologiji iz točke 2.2. po osam navedenih elemenata i 14 podelemenata. Radi ograničene dužine ovoga rada, cijeli postupak provođenja intervjua i ocjenjivanja ne može biti prikazan pa će se će se dati samo prosječna ocjena učinkovitosti rukovođenja, koja je 2,83 s indeksom koji iznosi $\mathbf{5 6 , 6 0} \%$. Oba podatka su unesena u Tablicu 2.

\subsection{Kadrovi - Staff}

Ocjenjivanje stanja kadrovske učinkovitosti obuhvaća elemenate kao što su: položaj djelatnika u proizvodnji i logistici, položaj djelatnika na rukovodnim radnim mjestima, zastupljenost visoko obrazovanih djelatnika, odnos neposredno pretpostavljenih djelatnika, edukacija i osposobljavanje djelatnika vremenski, ulaganje u edukaciju i osposobljavanje djelatnika financijski, udio gubitaka radnog vremena, prisutnost ozlijeda na radu, fluktuacija djelatnika i zapošljavanje. Kadrovska učinkovitost prema metodologiji iz točke 2.2. za zamišljeno proizvodno poduzeće ocijenjena je po deset navedenih elemenata i isto toliko podelemenata. Isto tako radi ograničene dužine ovoga rada, prikaz cijelog postupka izračuna i ocjenjivanja nije moguće prikazati pa će se dati samo prosječna ocjena učinkovitosti rukovođenja, koja je 3,35 i indeks učinkovitosti koji je 67,00\%. Oba podatka su unesena u Tablicu 2.

\subsection{Proizvodni program - Production program}

Osjenjivanje stanja učinkovitosti proizvodnog programa obuhvaća elemenate kao što su: prodaja novorazvijenih proizvoda sa povećanom dodanom vrijednosti, proizvodnja proizvoda sa većom dodanom vrijednosti, zadovoljstvo korisnika, reklamacije po kupcima, reklamacije financijski te trajanje razvoja novog proizvoda. Učinkovitost proizvodnog programa za zamišljeno proizvodno poduzeće ocijenjena je prema metodologiji iz točke 2.2. po šest navedenih elemenata i isto toliko podelemenata. $\mathrm{Na}$ osnovi već navedenih razloga dat će se samo prosječna ocjena učinkovitosti proizvodnog program,a koja je 2,83 s indeksom koji iznosi $56,65 \%$. Oba podatka su unesena u Tablicu 2.

\subsection{Prodaja proizvoda i usluga - Sales of products and services}

Ocjenjivanje stanja prodaje proizvoda i usluga obuhvaća elemenate kao što su zastupljenost novih tržišta, prisutnost u višem tržišnom segmentu, zastupljenost novih kupaca postojećeg proizvodnog programa, isporuke naručenih količina i obrada novih tržišta. Učinkovitost prodaje proizvoda i usluga za zamišljeno proizvodno poduzeće ocijenjena je prema metodologiji iz točke 2.2. po pet navedenih elemenata $\mathrm{i}$ isto toliko podelemenata. Isto tako radi ograničene dužine ovog rada cijeli postupak izračuna i ocjenjivanja ne može biti prikazan pa će se dati samo prosječna ocjena učinkovitosti prodaje i usluga, koja je 2,95 s indeksom koji iznosi $\mathbf{5 9 , 0 0} \%$. Oba podatka su unesena u Tablicu 2.

\subsection{Nabava i kooperacija - Procurement and cooperation}

Ocjenjivanje stanja učinkovitosti nabave i kooperacije obuhvaća elemenate kao što su: udio nabave nekurentnih ma- 
terijala i dijelova, vrijednost pravovremeno dostavljenih materijala i dijelova iz kooperacije, ovisnost prihoda o dobavljačima i kooperaciji, vrijednost nabave po dobavljaču i dijelova po kooperantu, vrijednost nabave po dobavljaču i kooperantu te aktivnost dobavljača i kooperanata. Učinkovitost nabave i kooperacija za zamišljeno proizvodno poduzeće ocijenjena je prema metodologiji iz točke 2.2. po pet navedenih elemenata i deset podelemenata. Iz istog razloga kao u točki 2.4. u daljem tekstu će se samo navesti prosječna ocjena učinkovitosti nabave i kooperacije koja je 2,93 s indeksom koji iznosi 58,50 \%. Oba podatka su unesena u Tablicu 2.

\subsection{Organizacija i informatizacija - Organization and computerization}

Ocjenjivanje stanja učinkovitosti organizacije i informatizacije obuhvaća elemenate kao što su: realizacija planiranih veličina, iskorištenje radnog vremena, stvarni i totalni škart, vrijeme dorade uvjetnog škarta, utrošak energije, nedovršenu proizvodnju, upravljanje zalihama gotovih proizvoda, upravljanje zalihama materijala, informatičku opremljenost, programsku podršku, ulaganje u web stranica i e-trgovanje. Učinkovitost organizacije i informatizacije za zamišljeno proizvodno poduzeće ocijenjeno je prema metodologiji iz točke 2.2. po dvanaest navedenih elemenata $\mathrm{i}$ isto toliko pripadajućih podelemenata. Iz navedenih razloga iz točke 2.4. u daljem tekstu navesti će se samo prosječna ocjena učinkovitosti organizacije i informatizacije, koja je 2,63 s indeksom koji iznosi $\mathbf{5 2 , 6 6} \%$. Oba podatka su unesena u Tablicu 2.

\subsection{Proizvodnja - Production}

Ocjenjivanje stanja učinkovitosti proizvodnje obuhvaća elemenate kao što su: vrijednost proizvodnje po djelatniku u proizvodnji, dobit po djelatniku u proizvodnji prije oporezivanja, utrošak materijala po djelatniku u proizvodnji, dobit po djelatniku u proizvodnji nakon oporezivanja, vrijednost tehnologije po djelatniku u proizvodnji, povećanje vrijednosti proizvodnje i nova tehnologija, vrijednost tehnologije i trošak održavanja te bruto osobni dohoci i vrijednost proizvodnje. Učinkovitost proizvodnje za zamišljeno proizvodno poduzeće ocijenjeno je prema metodologiji iz točke 2.2. po osam navedenih elemenata i isto toliko pripadajućih podelemenata. Iz već navedenih razloga u daljem tekstu dat će se samo prosječna ocjena učinkovitosti proizvodnje koja je 2,70 s indeksom koji iznosi $\mathbf{5 4 , 0 0 \%}$. Oba podatka su automatski unesena u Tablicu 2.

\subsection{Rast i razvoj - Growth and development}

Ocjenjivanje stanja učinkovitosti rasta i razvoja obuhvaća elemenate kao što su: kapitalna ulaganja i ukupni prihod, kapitalna ulaganja i amortizacija, troškovi promocije i ukupan prihod, ulaganja u istraživanje i razvoj prema ukupnom prihodu, ulaganja u istraživanje i razvoj te profit prije oporezivanja, kapitalna ulaganja prema profitu prije oporezivanja, rast ukupnog prihoda, ukupan prihod i vrijednost imovine te kapitalna ulaganja i razlika u povećanju ukupnog prihoda. Učinkovitost rasa ta i razvoja za zamišljeno proizvodno poduzeće ocijenjena je prema metodologiji iz točke 2.2. po devet navedenih elemenata i isto toliko pripa-

Tablica 1.

Table 1

\begin{tabular}{|c|c|c|c|c|c|c|}
\hline $\begin{array}{c}\text { R/B } \\
\text { Number }\end{array}$ & $\begin{array}{l}\text { ELEMENTI } \\
\text { ELEMENTS }\end{array}$ & $\begin{array}{l}\text { Jedinica mjere } \\
\text { Unit of } \\
\text { measure }\end{array}$ & 31.12.2015. & 31.12.2016. & 31.12.2017. & $\begin{array}{l}\text { Prosječna } \\
\text { ocjena } \\
\text { Average grade }\end{array}$ \\
\hline \multirow[t]{3}{*}{9.6.} & $\begin{array}{l}\text { Poslovna uspješnost } \\
\text { Business Success }\end{array}$ & & & & & 2,39 \\
\hline & $\begin{array}{l}\text { Ukupan prihod } \\
\text { Total revenue }\end{array}$ & kn & 45.769 .600 & 50.243 .700 & 68.945 .600 & 350.000 \\
\hline & $\begin{array}{l}\text { Prosječan broj radnika } \\
\text { Average number of workers }\end{array}$ & broj & 125 & 145 & 155 & 750.000 \\
\hline \multirow[t]{3}{*}{ 9.6.1. } & $\begin{array}{l}\text { Ukupni prihod po radniku = Ukupan prihod / } \\
\text { Prosječan broj radnika } \\
\text { Total revenue per worker = Total revenue / } \\
\text { Average number of workers }\end{array}$ & kn & 366.156 & 346.508 & $444.810,32$ & 1,95 \\
\hline & $\begin{array}{l}\text { Neto dobitak } \\
\text { Net gain }\end{array}$ & kn & 5.025 .700 & 6.873 .500 & 8.501 .100 & 35.000 \\
\hline & $\begin{array}{l}\text { Prosječnom broju radnika } \\
\text { Average number of workers }\end{array}$ & broj & 125 & 145 & 155 & 80.000 \\
\hline 9.6.2. & $\begin{array}{l}\text { Neto dobit po radniku = Neto dobitak / } \\
\text { Prosječan broj radnika } \\
\text { Net earnings per worker = Net earnings / } \\
\text { Average number of workers }\end{array}$ & kn & 40.205 & 47.403 & 54.845 & 2,76 \\
\hline
\end{tabular}


Tablica 2.

Table 2

\begin{tabular}{|c|c|c|c|c|c|}
\hline $\begin{array}{c}\text { R/B } \\
\text { Number }\end{array}$ & $\begin{array}{l}\text { FUNKCIJE } \\
\text { FEATURES }\end{array}$ & $\begin{array}{l}\text { Ocjena } \\
\text { Evaluation }\end{array}$ & $\begin{array}{l}\text { Intenzitet utjecaja } \\
\text { Impact intensity } \\
\%\end{array}$ & $\begin{array}{l}\text { Ponder - prosjek } \\
\text { Weight - average }\end{array}$ & $\begin{array}{l}\text { Učinkovitost } \\
\text { Effectiveness } \\
\%\end{array}$ \\
\hline 1. & $\begin{array}{l}\text { Učinkovitost rukovođenja poslovanjem } \\
\text { Business management effectiveness }\end{array}$ & 2,83 & 15,00 & 0,42 & 56,60 \\
\hline 2. & $\begin{array}{l}\text { Kadrovska učinkovitost } \\
\text { Personnel efficiency }\end{array}$ & 3,35 & 15,00 & 0,50 & 67,00 \\
\hline 3. & $\begin{array}{l}\text { Učinkovitost proizvodnog programa } \\
\text { Product program efficiency }\end{array}$ & 2,83 & 15,00 & 0,42 & 56,60 \\
\hline 4. & $\begin{array}{l}\text { Učinkovitost prodaje proizvodnog programa } \\
\text { Product Sales Effectiveness }\end{array}$ & 2,95 & 10,00 & 0,30 & 59,00 \\
\hline 5. & $\begin{array}{l}\text { Učinkovitost nabave materijala i kooperacija } \\
\text { Material procurement efficiency and cooperation }\end{array}$ & 2,93 & 5,00 & 0,15 & 58,60 \\
\hline 6. & $\begin{array}{l}\text { Organizacija i informatizacija poslovanja } \\
\text { Organization and computerization of business }\end{array}$ & 2,63 & 10,00 & 0,26 & 52,60 \\
\hline 7. & $\begin{array}{l}\text { Učinkovitost proizvodnje proizvodnog programa } \\
\text { Production efficiency of the production program }\end{array}$ & 2,70 & 10,00 & 0,27 & 54,00 \\
\hline 8. & $\begin{array}{l}\text { Učinkovitost rasta i razvoja proizvoda i poduzeća } \\
\text { Efficiency of growth and development of products } \\
\text { and businesses }\end{array}$ & 2,70 & 10,00 & 0,27 & 54,00 \\
\hline 9. & $\begin{array}{l}\text { Financijska učinkovitost poslovanja } \\
\text { Financial efficiency of the business }\end{array}$ & 2,30 & 10,00 & 0,23 & 46,00 \\
\hline & $\begin{array}{l}\text { INTEGRALNI INDEKS UČINKOVITOSTI } \\
\text { INTEGRAL PERFORMANCE INDEX }\end{array}$ & & 100,00 & 2,83 & 56,52 \\
\hline
\end{tabular}

dajućih podelemenata. Na osnovi prije navedenih razloga dat će se samo prosječna ocjena učinkovitosti rasta i razvoja, koja je $\mathbf{2 , 7 0}$ s indeksom koji iznosi $\mathbf{5 4 , 0 0 \%}$. Oba podatka su unesena u Tablicu 2.

\subsection{Financijska učinkovitost - Financial efficiency}

Ocjenjivanje stanja financijske učinkovitosti provodi se kroz sljedeće elemente: profitabilnost i rentabilnost, financijska aktivnost, financiranje i financijska stabilnosti, zadu- ženost, likvidnost i poslovna uspješnost. $U$ tablici 1 dat je primjer izračuna dva podelementa i to relativnog iznosa ukupnog prihoda po radniku i relativnog iznos neto dobiti po radniku. Oba iznosa su dali ulazni podatak za izračun ocjene po formuli (2) iz točke 2.2. Tako je ukupni prihod po radniku ocijenjen sa $\mathbf{1 , 9 5}$, a neto dobiti po radniku sa 2,79 što u prosijeku daje ocjenu poslovne uspješnost od 2,39. Inače financijska učinkovitost zamišljenog proizvodnog poduzeća ukupno je ocijenjena po šest navedenih ele-

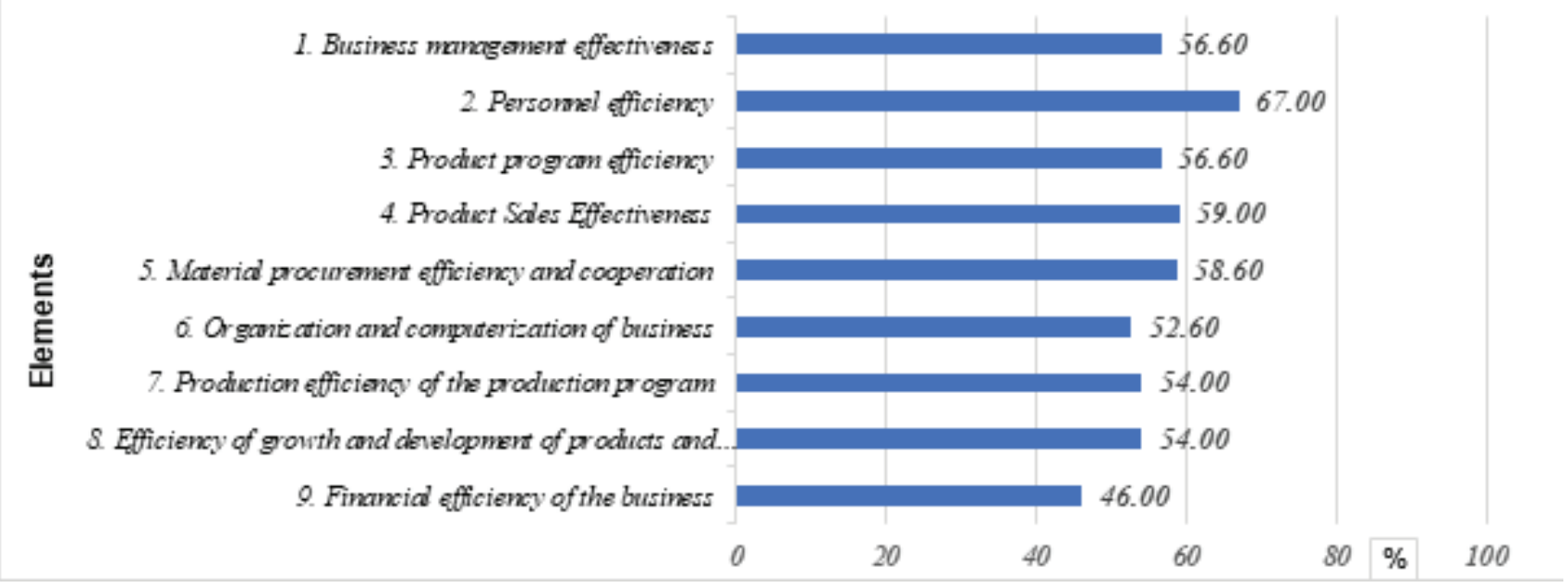

Graf 1. Prikaz indeksa učinkovitosti po funkcijama proizvodnog poduzeća Graph 1 Performance index by production company function 
menata i dvadeseti jednim podelementom. Iz naprijed navedenih razloga dat će se samo prosječna ocijena učinkovitosti proizvodnje koja je 2,30 s indeksom koji iznosi 46,00 \%. Oba podatka su unesena u Tablicu 2.

\subsection{Integralna učinkovitost proizvodnog poduzeća - Integral efficiency of a manufacturing company}

Integralna ocjena stanja učinkovitosti za devet funkcija zamišljenog proizvodnog poduzeća prikazanih u tablici 2 i grafu 1. izračunata je nakon automatskog unosa ocjena i indeksa i prethodnih devet tablica koje nisu mogle biti prikazane radi ograničene dužine ovoga rada. Tako unesene prosječne ocjene u tabelici $2 \mathrm{u}$ istoj se množe sintenzitetom utjecaja i dobije se prosječna ocjena od 2,83 što daje indeks učinkovitost zamišljenog poduzeća od $\mathbf{5 6 , 5 2} \%$.

\section{ZAKLJUČAK CONCLUSION}

Minimalna učinkovitost u odnosu na željeno stanje prema intenzitetu pojavnosti trebala bi se kretati od $\mathbf{2 0 , 0 0} \%$ do $\mathbf{7 0 , 0 0} \%$, djelomično zadovoljavajuće stanje učinkovitosti u odnosu na željeno prema intenzitetu pojavnosti trebalo bi se kretati od 71,00 \% do 90,00 \%, zadovoljavajuće do željenog stanja učinkovitosti u odnosu na željeno prema intenzitetu pojavnosti trebalo bi se kretati od $\mathbf{9 1 , 0 0} \%$ do $100,00 \%$

Učinkovitost zamišljenog proizvodnog poduzeća drvno prerađivačke industrije u 2017. godini u odnosu na željeno stanje po funkcijama je minimalno i kreće se u rasponu od $\mathbf{4 6 , 0 0} \%$ do $\mathbf{6 7 , 0 0} \%$ s integralnim indeksom od $\mathbf{6 5 , 5 2} \%$. Prema tome zamišljeno proizvodno poduzeće je najmanje učinkovito na područjima rukovođenja, razvoja inovativnih i promociji novih proizvoda, u organizaciji poslovanja i proizvodnji, digitalnoj transformaciji te rastu i razvoju, što je rezultiralo lošom financijskom učinkovitošću.

Radi kratkoće ovoga rada nije se moglo prikazati sve automatski dobivene grafikone po funkcijama iz kojih bi se, potpuno razvidno, mogla vidjeti neučinkovitost svakog ele- menta u okviru rukovođenja, razvoja inovativnih i promociji novih proizvoda, u organizaciji poslovanja i proizvodnji, digitalnoj transformaciji, rastu i razvoju te financijama. Na taj način moglo bi se jednostavno detektirati u kojim bi elementima trebalo uvesti promjene u poslovanju i to najvjerojatnije uz potrebu korištenja vanjskih stručnih kapaciteta.

Iz svega navedenog može se zaključiti da se sa primjenom metodologije integralnog indeksa učinkovitosti u malim i srednjim poduzeća drvno prerađivačke industrije mogu u roku od tri do peta dana uspješno detektirati područja s opsegom potrebnih promjena i poboljšanja u poslovanju, a sve u cilju stalnog približavanja izvrsnosti i povećanja konkurentnosti.

\section{LITERATURA}

\section{LITERATURE}

- [1] ABC Design Ltd: (2000) The performance track/ Bench marking index (projekt)

- [2] Mikić, M.: (2009) Upravljanje troškovima u malim i srednjim proizvodnim poduzećima (pregledni znanstveni rad UDK 657.47:65.017.2/.3 Zagreb)

- [3] Dujanić, M.: (2004) Upravljanje promjenama u poduzeću (znanstveni rad UDK 658.5:65.01. Rijeka)

- [4] Vusić D.: (2016) Poslovna izvrsnost (izvorni znanstveni rad UDK 649.5:64.01 Varaždin)

- [5] Oslić I.: (2005) Kvaliteta, izvrsnost i održivost, (članak u glasilu Gospodarstvo i održivost)

- [6] Milovac J.: (2008) Ponašanje menadžera u organizaciji - put prema poslovnoj izvrsnosti (završni rad Specijalistički stručni studij Šibenik)

- [7] UHY Rudan, Rudan D.: (2018) Financijski pokazatelji ( predavanje Zavod za organizaciju proizvodnje, Šumarski fakultet, Sveučilišta u Zagrebu)

- [8] Grebenar V.: (2016) Holistički pristup izračunu poslovne učinkovitosti po segmentima za potrebe kratkoročnog izvještavanja (doktorska disertacija Sveučilište Josipa Jurja Strossmayera u Osijeku, Osijek)

- [9] Biondić D.: (2015) Simulacija integralnog ocjenjivanje indeksa učinkovitosti industrije namještaja $\mathrm{C} 31$ (projekt)

- [10] https://www.celonis.com/

\section{SUMMARY}

This paper aims to present in a short form a relatively simple methodology of integral performance evaluation and the possibility of its application in small and medium-sized timber industrial enterprises. With some adjustments to the assessment elements, the method is applicable in all industries and services. Integral performance evaluation is in the function of achieving business excellence. The performance appraisal method itself involves benchmarking against the desired state and partly an in-depth analysis of operating results. Integral performance appraisal involves the systematic comparative review of the results achieved by the elements, functions and organization as a whole. In a narrow format, the method, based on the perception of business results in relation to the desired situation, can be applied to self-assessment of the timber industry business with the prior brief management training. A more objective assessment of effectiveness through detailed implementation of the 
methodology can be achieved through the engagement of an interdisciplinary team of consultants. The management and all employees of the company should be open for cooperation during the consultants' work in the company. Collaboration with consultants to protect the confidentiality of company data, includes analysis of documentation, recording and reviewing technical and economic data, interviewing employees at all levels, interviews of stakeholders from the environment and calculating all coefficients, shares and rates that can be compared to the desired situation. In addition, in a very abbreviated form, information will be provided on the integral estimates of the performance index by element, function and organization as a whole for an imaginary firm that manufactures solid wood furniture that produces furniture according to customer's designs.

For the sake of brevity, this could not show all the automatically obtained graphs by function, which could clearly show the inefficiency of each element in the management, development of innovative and promotion of new products, in the organization of business and production, digital transformation, growth and development. and finance. In this way, it would be easy to detect in which elements changes in the business should be introduced, most likely with the need to use external expertise.

The integral performance evaluation for the nine imaginary manufacturing company features shown in Table 2 and Chart 1 . was calculated after the automatic entry of ratings and indices and the previous nine tables that could not be displayed for the limited length of this paper. The average scores so entered in Table 2 are multiplied by the intensity of the impact and an average score of 2.83 is obtained, which gives an imaginary enterprise efficiency index of 56.52\%. See table 2 INTEGRAL PERFORMANCE INDEKS and Graph 1. Display of performance index by manufacturing company functions The minimum efficacy with respect to the desired incidence rate should range from $20.00 \%$ to $70.00 \%$, and the partially satisfactory efficacy ratio with respect to the desired incidence rate should range from $71.00 \%$ to $90.00 \%$, satisfactory to the desired state of efficacy with respect to the desired one according to the intensity intensity should range from $91.00 \%$ to $100.00 \%$

The efficiency of an imaginary manufacturing company in the wood processing industry in 2017 relative to the desired state by function is minimal and ranges from $46.00 \%$ to $67.00 \%$ with an integral index of $65.52 \%$. Consequently, a thoughtful manufacturing company is the least effective in the areas of management, innovation development and new product promotion, business organization and production, digital transformation, and growth and development, resulting in poor financial efficiency.

From all of the above, it can be concluded that with the application of the methodology of integral efficiency index in the small and medium enterprises of wood processing industry, within three to five days, the areas with the scope of necessary changes and improvements in business can be successfully detected, all with the aim of constant approaching excellence and increasing competitiveness.

KEY WORDS: business excellence, efficiency, integral approach, performance appraisal, interdisciplinary approach, perception, desired state, introduction of changes in business 